\title{
Effect of Office Ergonomics on Office Workers' Productivity in the Polytechnics, Nigeria
}

\author{
Edna Ikwubiela Baba ${ }^{1} \quad$ Danjuma David Baba ${ }^{2}$ James Omatule Oborah ${ }^{1 *}$ \\ 1.Department of Office Technology and Management, The Federal Polytechnic, Idah, Nigeria \\ 2.Department of Languages, The Federal Polytechnic, Idah, Nigeria
}

\begin{abstract}
The research is sponsored by the Tertiary Education Trust Fund (TETFUND), Institution-based research grant Abstract

The study was anchored on the ergonomic theory of production and design that stress the importance of office workstation as imperative for workers enhanced productivity. Quasi-experimental design was used to determine the relative performance of office workers with ergonomically fitted furniture, equipment and environment on their keyboarding tasks performance. The study lasted for three months with the post-test results indicating better performance from the experimental group. This implies that office workers with ergonomically fitted furniture, equipment and environment in the tertiary institutions in Nigeria are likely to have enhanced work output. Therefore, the institutions should be provided with well-furnished office with appropriate technological devices and environment.
\end{abstract}

Keywords: Office ergonomics, ergonomics, Office workers, Productivity, Keyboarding, work environment

DOI: $10.7176 / \mathrm{JEP} / 12-3-10$

Publication date: January $31^{\text {st }} 2021$

\section{Introduction}

Ergonomics is derived from two Greek words "ergon" meaning work, and "nomoi" meaning natural laws. In a simpler term it is the study of the nature of work done, the environment it is done and the tools available to do the work. Ergonomics is all about comfort and efficiency which enhances productivity and work force satisfaction. It is the interaction between people and the objects they use and the environments they function in. if equipment, workstations and work methods are designed to suit employee capabilities and limitations, health, safety and performance is maximized. Ergonomics is fitting the task to the person. Ergonomics improves health and safety, reduces costs from absence and reduced productivity, and ensures that social and legal obligations of employers to their employees are being met (Emmanuel, Jonathan and Ayodeji, 2014).

Ergonomists study human capabilities in relation to work demands. Human factors and Ergonomics also known as comfort design, functional design, and user-friendly, systems, is the practice of designing products, systems or processes to take proper account of the interaction between them and people. In essence it is the study of designing equipment and devices that fit the human body and its cognitive abilities. The two terms ergonomics and human factors are essentially synonymous.

Posture in the context of ergonomics according to Merriam-Webster dictionary "is the way in which your body is positioned when you are sitting or standing. From an evolutionary perspective, man was originally a hunter/gatherer. This function puts strong emphasis on changing positions quickly, being flexible and calculating. A strong and well-trained body increases survival in a hostile environment. From an anatomical standpoint the upright, the postural muscles mainly support standing, and sitting body positions. These can be active for long time periods, need only moderate variation of body position changes that can carry your body the whole day. When the body is well balanced, fatigue takes a ling time to develop. However, if you withdraw from the balanced position by lifting your arms up, stooping, or leaning to the side, you activate your phasic muscles, which are the shoulder girdle and the phasic neck muscles. These are muscles that fatigue easily, and accumulate lactic acid causing muscular pain and stiffness. Try to hold out your arms to the side for as long as you can. Few can manage for 5 minutes before your shoulders begin to feel stiff. This is what any static body position away from the balanced posture will do. Dynamic and varied body positions will allow your muscles to adapt and give them the appropriate oxygenated blood-flow. A head tilted forward or backward away from the resting position will create muscular tension and pain (Lennart, Jasminka, and Ida, 2015) .

The international ergonomic association defined ergonomics (or human factors) as the scientific discipline concerned with the understanding of interest among humans and other elements of a system, and the profession that applies theory, principles, data and methods to design in order to optimize human well-being and overall system performance. Similarly, Oborah (2011), sees ergonomics as the science of designing work processes and equipment foe employees and should be considered when there are injuries, complaints, staff turnover or absenteeism from work. One method of solving an ergonomic problem or complaint is to adjust the employees workstation.

Shin, and Hegde, (2010) posited that ergonomic requires the following steps: recognizing the complaint/problem and documenting the job tasks; evaluating the existing situation; consulting resources/experts 
on best practices; identifying mismatches between the existing situation and human capabilities; identifying potential solutions; providing recommendations and implementing the recommendations; and evaluating the success of the recommendations.

Lennart, Jasminka, and Ida, (2015) asserted that the basic premise is that working conditions should be designed around the workers themselves. Good ergonomic practice is important to avoid discomfort and reduce the risk of Repetitive Strain Injuries (RSI) such as Carpal Tunnel Syndrome and other musculoskeletal disorders, which can develop over time and can lead to long-time disability. This means that your equipment and your workplace should be arranged to suit your individual needs. Ergonomic and human factor according to the international ergonomic association is employed to fulfill the goals of occupational health and productivity. It is relevant in the design of such things as safe furniture and easy-to-use interfaces to machines and equipment. Ergonomic and human factors is concerned with the fit "between the user, the equipment and their environment. It takes account of the users capabilities and limitations is seeking to ensure that tasks, furniture, information and the environment suit each user

The strategic position which the office occupies in any given organization as the information nerve center has in turn place emphasis on ergonomics. The universal nature of the office has made it a place of action, where various functions necessary for information handling are performed and each function involves the utilization of one of technology or another. Generally the office is basically concerned with information as its sole product (Agomuo 2005).

The office has been described as a place where administration that is the management and handling of information takes place. Kalu (2009) defines an office as that part of an organization which provides all kinds of information required for efficient management and control of the operations of the entire organization. Office workers therefore, are persons who perform the functions of an office which include information-related (i.e routine/basic) functions as well as administrative/management functions.

Polytechnic education is one of the tertiary levels of education given after secondary school. Awodi, (2019) and Ogungbe, (2020) describe polytechnic as tertiary educational institution in Nigeria with two tier programme of studies that consist of National Diploma and higher Diploma with one year industrial experience as one of the pre-requisites for HND programme. The objectives of polytechnic education, as stated in the National Policy on Education (FRN,2009), are to provide full-time course of instructions and training in engineering, other technologies, applied sciences, business and management leading to the production of trained manpower, to provide the technical knowledge and skills necessary for occupational development in Nigeria as well as to give training and impact necessary skills for the production of skilled personnel who shall be enterprising. This study will concentrate on the effects of ergonomic practices on productivity of office workers in Polytechnics in NorthCentral, Nigeria with a view to verifying empirically how equipment and workplace are arranged to suit individual needs.

\section{Statement of the problem}

Musculoskeletal pain has been an important issue over the decades among office workers. Whether caused or just aggravated from poor posture, or inappropriately adjusted workstations, the issue continues to be a challenge to staff, employers and ergonomists. Safety and accident prevention concerns managers for several reasons, one of which is the staggering numbers of work-related accidents. Injuries or illness occur among workers. Computers contribute to stick syndrome symptoms like headache and sniffles, which some experts blame on poor ventilation and inappropriate choice of right ergonomic office furniture. Office work is susceptible to other health and safety problems, including repetitive trauma injuries related to computer use, respiratory illness stemming from indoor are quality, and high level of stress, which are associated with a variety of factors, including task design.

In addition to poor ergonomic effect on health of office workers, productivity is another consideration in the overall effect of ergonomic. The question therefore is that, to what extent do ergonomics practices influence musculoskeletal pains and productivity of office workers in Polytechnics in North-Central, Nigeria? There are no empirical evidence to answer this question. This provoke the study on the effects of ergonomic practices on productivity of office workers in Polytechnics Nigeria.

\section{Objectives of the study}

The objectives of the study are as follows:

1. To determine the effects of ergonomic practices of office workers in relation to furniture use.

2. To determine the effects the ergonomic practices of office workers in relation to machine operation.

3. To determine the effects the ergonomic practices of office workers in relation to office layout.

\section{Review of Related Literature}

\subsection{Ergonomic Practices of Office Workers In Relation To Furniture Use}

Working in an office involves spending a great deal of time sitting in an office chair-a position that adds stress to 
the structures in the spine. Therefore, to avoid developing or compounding back problems, it is important to have an office chair that is ergonomic and that supports the lower back and promotes good posture. Oborah (2011) is of the view that an office worker should listen to his body because this would help in noticing that something is wrong through those aches and pains. But often office workers choose to ignore the neck strain, headaches, tight shoulders, fatigue eyes, and occasional wrist pain.

O'Neill, and Albin, (2012) stated that the chair is one of the important parts of your. It determines the posture of your back, arms and legs and encourages good posture and circulation. An ergonomic chair should have seat height and be easily adjustable. A pneumatic adjustable easiest way to do this. A seat heath that ranges from about 16 to 21 inches off the floor should work for most people. This allows the user to have his or her feet flat on the floor, with thighs horizontal and arms even with the height of the desk.

According to Gold, Driban, Yingling, and Komaroff (2012), the seat should have enough width and depth to support any user comfortably. Usually 17 to 20 in e is the standard. The depth (from front to back of the seat) needs to be enough so that user can sit with his or her back against the backrest of the ergonomic office chair while approximately 2 to 4 inches between the back of the knees and the seat of the chair.

Again, the authors stated that the lower back support in an ergonomic chair is very important. The lumbar spine has an inward curve, and sitting for long periods without support for this curve tends to lead to slouching |(which flattens the natural curve) and strains the structures in lower spine. An ergonomic chair should have a lumbar adjustment (both height and depth) so each user can get the proper fit to support the inward curve of the lower back.

In general, one should be able to sit in the chair with feet flat on the floor, knees and hips at about 90 degrees. The sear depth should allow approximately two fingers of space between knees and end of seat. The low back should be supported by the back of the chair. The curve in the back should match the curve in the chair. Some employees prefer additional support to the upper back area (high back). Arm rests should be adjustable to prevent interference with the keyboard tray and to other tasks. Chairs should be adjustable to allow for tilting between 95 and 110 degrees. This allows one to push back and alternate positioning as needed for comfort (Emmanuel, et al 2014).

Furthermore, according to the authors, the back rest of an ergonomic office chair should be 12 to 19 inches wide. If the backrest is separate from the seat, it should be adjustable in height and angle. It should be able to support the natural curve of the spine, again with special attention paid to proper support of the region.

The seat material should have enough padding to be comfortable to sit on for extended periods of time. Having a cloth fabric that breathes is preferable to a harder surface. Similarly, he suggests that office chair armrest should rest lightly, and the forearm should not be on the armrest while typing. Arms rest, if available, should allow for arms or elbows to rest comfortably, also at 90 degrees. It is important that arms and shoulders are resting comfortably while typing.

Gold, Driban, Yingling, and Komaroff (2012) posited that the upper arms should be vertical (or close to it), and forearms should be horizontal (or close to it) so that there is approximately a right angle at the elbows. With the shoulders relaxed, the elbows should be levelled with the desk or very slightly above. Any conventional style or ergonomic chair should easily swivel or rotate so the user can reach different areas of his desk without straining.

Oborah (2011) stated that the work surface or desk should be large enough to position equipment to the individual users' comfortable reach and provide space in front of the keyboard to support the wrists/forearms of the user $(5 \mathrm{~cm}$ to $10 \mathrm{~cm})$. The surface according to Oborah, should have adequate leg-room to achieve a comfortable working position. Consideration should be given to a surface which is large enough to allow associated tasks to be carried out.

Desks are usually a standard height of about $720 \mathrm{~mm}$. This is fine for most people, but effort should be made to check to make sure that all users can be seated comfortably at a desk of this height. Particularly short or tall people may need an adjustable-height desk. Enough desk space is needed for paperwork, the computer (monitor, keyboard and mouse) and any additional equipment that are needed to do the job. The desk should not have any obstructions underneath like drawers or supports that force the user to sit in uncomfortable positions. Computer desks should also have a fairly 'thin' top-not like a kitchen worktop. This is to make sure that the user can get the legs under without squashing the thighs (Sohbat, Oly, Haider, Mohiuddin and Probha, 2015).

Emmanuel, et al (2014) pointed out that employees may need to adjust chair (move higher) when relocating from computer workstation to desk area as generally desks are positioned higher than are keyboard areas. While working at a desk, arms should continue to remain at a comfortable, neutral position so that arms are at about 90 degrees at the desk, and shoulders are not hunched upwards.

Ahmed-Refat, Abdullah, Saha, and Rehab (2008) opined that the shoulders, arms and wrists should be in relaxed positions. While seated, arms should be at about 90 degrees to the body, with shoulders relaxed and wrists in a neutral position. Holding tensed muscles in a fixed or awkward position for long periods of time is called static work. Static work results in a burning sensation discomfort and fatigue because there is decreased blood flow to the tensed muscles. Fatigue leads to a buildup of waste materials as a muscle level, known as lactic acid. 
When fatigued the load is transferred to the tendons and ligaments. With time, this can lead to cumulative injuries (i.e repetitive strain). Work heights have a major impact on job performance and musculoskeletal injuries. Working too high, with arms held away from the body (abduction), and shoulders lifted, contributed to static loading. Working too low results in employees bending forward which can lead to neck and back pain.

\section{Ergonomic Practice of Office Workers In Relation To Machine Operation}

Gary (2008) asserts that even with advances in computer screen technology, there is still risk of monitor-related health problems at work. Problems include short-term eye burning, itching, and tearing, as well as eyestrain and soreness. Backaches and neck aches are widespread. These often occur because employee tries to compensate for monitor problems (such as glare) by maneuvering into awkward body positions. There may also be tendency for computer users to suffer from cumulative motion disorders.

The old type of monitors used a cathode ray for projection. They were big, bulky and heavy with low luminance with a tendency to flicker. Today, most of these monitors have now been replaced with liquid crystal, plasma or light emitting diodes. These are thinner, lighter and more luminescent with better resolution. Some screens use interactive software, so you can elicit commands by pointing directly on the screen and the font size can easily be changed to provide better acuity.

The keyboard and mouse should also be easy to use; it should be obvious how they work, and using them should not require any physical effort (Ahmad, Amin, and Ismail, 2009). The monitor display should be clear and easy to read, adjustable for colour, contrast, brightness, tilt and swivel, and have no flicker. It is very important that when one uses a computer he should be able to work in a posture which is comfortable and which does not place him on long- term health at risk. For instance, sitting in a slumped posture can case back pain and long- term back injury. The key to avoiding this is to work in what ergonomists call a 'neutral posture'. This makes sure that no unnecessary strain is placed on the nerves, muscles, tendons, ligaments and bones. To get this right, the layout of the computer equipment on the desk is important, as well as the adjustment of the chair. Keep key objects such as your telephone, stapler or printed materials close to the body to prevent excessive stretching. Stand up to reach anything that cannot be comfortable reached while sitting.

Place the mouse within easy reach on the side of the keyboard. Keep the wrist in a natural and comfortable position when using the mouse. Use a wrist rest to minimize stress on the wrists and prevent awkward wrist positions. While typing, hold hands and wrists above the wrist rest. During typing breaks, rest the heels or palms of the hands not the wrist rest. When typing wrists in a straight, natural position not bent up, down or to either side (O’Neill, 2013).

Oborah (2011) states that the body, monitor and keyboard should form a straight line. Adjust setup to rotate trunk or neck to type or view the screen. Take periodic breaks and / or vary tasks to help reduce discomfort, fatigue, or repetitive strain injuries. The mouse and keyboard is positioned so that the forearms are horizontal. The shoulder and arms are relaxed and comfortable. The mouse should be placed close to the keyboard and it should be used without leaning over to the side.

The wrists and hands should be straight, in line with the forearms, and relaxed. Place the keyboard in front with enough room to rest the hands when not typing. Make sure that the keyboard is as flat as possible to reduce the upwards angle of the wrists. Positioning the keyboard away from the body will hell help to reduce the sideways bending of the wrists too. Avoid resting the wrists on the hard edge of the desk and putting pressure on the soft tissues on the inside of the wrist (Agboola, 2011).

The keyboard should be separated from the screen and adjustable in position and tilt, both in relation to the screen and to the convenience of the operator. It should be adequate size, have legible symbols and be constructed of a non- reflective material with a matt surface. The design and arrangement of the keyboard and the characteristics of the keys should be adequate to facilitate the effective use the keyboard.

The monitor should not be poorly placed. Poorly placed monitor according to the author may put extra strain on your eyes and upper spine, especially the neck. Position the screen to minimize reflections and glare from lights and windows. The display screen should be adjustable in swivel, tilt and contrast to present a clear and stable image free from distracting glare and reflections. The screen should be slightly below eye level for comfortable viewing. This can help reduce neck strain (Shin and Hegde, 2010).

The laptop, notebook, iPad and smartphone are all easier to move around than traditional desktop computers. Complying with the ergonomic principles may however be a challenge. Keyboards and monitors of laptops are unavailable to adjust individually, so in order to maintain a neutral sitting position, a typical solution would be to place the laptop on a stand at eye level and connect a separate keyboard. Another solution may be to use a docking station with a separate monitor, and to use your laptop as a central processing unit (CPU). Since the keyboard and monitor of laptops are connected, they are not possible to adjust individually. When using smartphones for playing games for long time periods, a horizontal position (laying in bed) may probably be recommended from an ergonomics standpoint (Gustafsson, 2012). 


\section{Ergonomic Practices of Office Workers In Relation To Office Layout.}

The design of the office is an important factor for general well-being, and may occasionally be the source of audiovisual stress, significantly increasing muscular tension that may lead to decreasing postural adjustment and cause muscular discomfort.

Historically, a totally open landscape from the past now tends to be replaced by various wall heights around individual workstations. Building a partially or totally enclosed room/cubicle in this type of environment is often made more appealing with decorations, plants and harmonic colours.

Indoor air quality is another important factor to insure comfort in the work place. The American Society of Heating Refrigerating and Air-conditioning Engineers (ASHRAE) publishes regularly updated standards on ventilation for acceptable indoor air quality.

Jacobs, Foley, Punnett, Hall, Gore, Brownson, Ansong, Markowitz, McKinnon, Steinberg, and Ing (2011) posited that air conditioning is another factor that may affect the employees' well-being. Lower humidity can increase those sensitive to respiratory tract infections, and humidity levels below $20 \%$ can increases the annoying effect of an electric spark when touching metal surfaces. Also, cold air coming down from an overhead vent can lead to annoying pain and muscle tensions. Various odours may also cause distress in workers. We have encountered strong smelling conditions that were caused by a dead rat, leftover food in office cabinets, and water leaks causing mold. There is no doubt that inadequate air quality (IAQ) problems will lead to distress, which may increase muscular tension, and also aggravate musculoskeletal pain disorders.

Jacobs et al (2011) noted that Working at the monitor can be stressful on the eyes, and lead to discomfort such as light sensitivity, dry and itchy eyes. Helpful suggestions to consider to correct these discomforts are need for reading glasses, increase font size, and adjust the monitor screen for brightness, glare, contrast, and any annoying flickers. To avoid eyestrain, adjust the height and distance of the monitor. The monitor should not be placed against a light background such as a window, and should be free from any light reflections or flickering. It should be placed an arm length distance from the body, and the first line of the text on the monitor should be viewed without moving the head up or down. For those who use bifocals, it is important to look at the monitor through the bottom part of the eye lens. Annoying neck strain can arise when positioning the head back. When viewing the monitor through the lower portion of eye glasses, position the monitor accordingly so the head remains up right. It is important to see an ophthalmologist regularly, especially if having persisting eye problems. Painful and red eyes can be a sign of a serious problem such as glaucoma (elevated eye pressure) or allergies. Dry eyes occur when there is insufficient fluid in the eyes. This may commonly be caused by illnesses such as allergies, and rosacea

An office is a room where professional duties and a administrative work is carried out. The details of the work depend on the type of business that you are involve in, but will usually include using computers, communicating with others by telephone or fax, keeping records and files etc. Features of an office such as people, space, equipment, furniture and the environment, must fit together well for workers to feel healthy and comfortable and to be able to work efficiently and productively (Idowu et al 2005).

Ergonomics can be allied to offices in several ways. You could look at how the office is laid out, including where people sit in relation to equipment, windows and doors. You could check that equipment and furniture is suitable before the type of work that people are doing. This includes seating, desks, computers, printers and anything else that they might use to do their job (O'Neill (2010). You could assess the environment that is, the temperature, ventilation, lighting, decoration. All these aspects of an office are considered in relation to the individuals in the office with emphasis on their safety, health, comfort- and productivity.

Kalu (2009) defined office layout as the arrangement of furniture and equipment and placing of staff inside a single office floor space so that the best use could be made of the space involved in attaining maximum efficiency. The layout of the office is determined by the nature of the business activities of the office, the size and nature of the rooms or buildings available.

The author further stated that office layout is the available office floor space meant to be occupied by the office workers and equipment. It is not enough for an office to be properly located and laid out, it is also highly necessary to ensure that good physical conditions are provided and at the same time well maintained. This includes arranging where people need to sit and work in the office, according to who they work with- their teams perhaps, what equipment they need to do their job and what sort of working environment they need. Some people may need a very quiet area to work, for example if they need to concentrate, and could be put in a separate area away from noisy people and equipment. Other people may need to work creatively in teams, and would be better off in a relaxed, open plan area. If the office has shared equipment, such as printers and scanners, they needs to be easily accessible to everyone who needs to use them (Agboola, 2011).

Another feature of an office according to (Ahmed- Refat et al 2008) is the environment, or surroundings, in which you are working. This includes temperature, ventilation, humidity, lighting, noise etc. The environment or the surrounding within which office work is performed and which affects the prestige of the enterprise, the health, the moral and efficiency of the workers is very important. 
The importance of office environment according to the authors is that the worker will generally puts in the best under a contusive working environment since the brain and the human body are intimately connected and the efficiency of the worker depends on his physical and mental fitness. Consideration must be given to the positioning of furniture and equipment in relation to sources of light, heat and ventilation as well as to the convenience, cleanliness, first aid working practices of the individual user. Trip hazards such as trailing cables should be avoided by the use of cable management where required.

Lighting is very important. Office lighting is so important that work cannot be carried on effectively without it. Where the lighting is poor, it causes eye strain to the workers and consequently they produce inferior quality work. Most people like to be able to see daylight as it gives them a feeling about how the day is going outside and natural light is also thought to make people feel better too. Monitors need to be positioned facing away from windows so that there is no glare or reflection on the screen. According to Lennart, Jasminka, Sandra, and Ida, (2015), patches of bright light on the screen make characters harder to read and can force you into uncomfortable positions as you try to see around the bright patch. Blinds can be used at windows to cut down glare.

Shared items such as computer manuals, stationery supplies, etc., need to be stored so that everyone can access them. In large or busy open plan offices, the layout needs to be planned very carefully, as many people with different jobs will be using area. Also, if space is restricted, the layout becomes important to ensure that the working space is not too cramped, and people do not get in each other's way. Access and emergency routes need to be defined and laid out to ensure that people can move around the office easily and quickly if necessary.

\section{Theoretical Framework}

Theories of ergonomics are interrelated and mostly emphasised the interactions between people, product and the environment (Wilson, 2000 \& Laurig and Vedder, 2020). When the interactions fit the required ergonomics rule, it is expected that strains would the reduced on the workers, thereby enhancing productivity. Ecological theory of ergonomics fit in the context of this study. The proponents of the theory (Saunter and Swanson, 1996) proposed that the office tools, technologies and the nature of work affect both organisation factors and physical demands of work. Individual factors were also discovered to moderate the effects of the office ecological environment as propounded in the theory. In the context of this study, it is proposed that the work tools, physical office environment and the office workers are the necessary components of the ergonomic practice that were studied.

\section{Methodology}

The study involved the 50 newly recruited and volunteered interns office workers for the population. Quasiexperimental design was used for the study and a sample of 30 of the interns office workers was randomly selected and assigned into two groups - experimental and control group:

\begin{tabular}{|l|c|c|c|c|}
\hline \multirow{2}{*}{$\mathrm{N}$} & Group 1 & O1 & $\mathrm{X}$ & O3 \\
\cline { 2 - 5 } & Group 2 & 03 & $\mathrm{X}$ & O4 \\
\hline
\end{tabular}

R: Randomisation, Group 1: Experimental Group, Group 2: Control Group, O1: Pre-test, X: Treatment and $\mathrm{O} 2:$ Posttest

The 50 newly interns office workers were National Diploma graduates of the Department of Office Technology and Management, the Federal Polytechnic, Idah, Kogi State for 2017. By randomisation, two groups (experimental and control) emerged, with a total of 30 and 15 each in the respective groups. A pre-test (5-minutes timed-writing) was administered to the two groups under the same conditions (furniture and environmental conditions). While the experimental group had their environmental conditions improved with air conditioners, ergonomically furnished (swivel chairs and workstation computer desks) rooms and equipment (desktop computers, mouse pad), the control group did not have this opportunity but continued with less comfortable furniture (typist table with padded wooden chairs and equipment (desktop computers without mouse pad). After three months' work, the two groups were given three hours to work on a straight-copy documents which was the post-test for the research study. The three hours given would be adequate to reveal the impact of ergonomically fitting work conditions on the interns office workers. At post-test, one member each dropped from the groups and the study was left with 28 members. The data generated was analysed using the following hypotheses as a guide:

1. There is no significant difference in pre-test mean score of the Experimental and Control groups

2. There is no significant difference in the post-test mean score of the Experimental and Control groups.

3. There is no significant difference in the post-test mean score of the Male and Female in the Experimental Group

The null hypotheses were tested at 0.05 level of significance at a two-tailed t-test with degree of freedom (df) of 26. The decision is taken to reject a null hypothesis if the P-value (t-calculated) is less than alpha value (table t'), reject the null hypothesis. If the result is greater than the table t', null hypothesis is not rejected. If the null hypothesis is rejected, this implies that the alternative hypothesis is correct, and that the data is significant and. If the null hypothesis not reject, it implies that the data is not significant and there is no significant difference in the performance of the two groups. 


\section{Presentation of Results}

The results of the study are presented in table according to the formulated hypotheses as follows:

1. There is no significant difference in pretest mean score of the Experimental and Control groups

Table one contains the data that was used to test the hypothesis. That data was generated from the pretest administered on the experimental and control groups of 14 members each.

Table 1

t-test of Pretest Mean Score of the Experimental and Control Group

\begin{tabular}{|l|r|r|l|l|l|}
\hline Groups & Mean & t-cal & Ttab & Df & Decision \\
\cline { 1 - 2 } Experimental (14) & 125.43 & -0.62 & -1.71 & 26 & Not Significant \\
\cline { 1 - 2 } & 137.43 & & & & \\
\hline
\end{tabular}

$\mathrm{N}=28$

The data presented in table one reveals a slightly higher mean for the control group, but the t-test shows no significant difference between the Experimental and Control groups with a t- cal ( $t$ ' calculated) of -0.62. The t-cal is greater than the t-tab (table t') of -1.70 . Therefore, the null hypothesis of 'no difference' is not rejected - the two groups performed equally. The Experimental and the Control groups showed no significant difference. The two groups have the same capacity at the commencement of the study.

2. There is no significant difference in the posttest mean score of the Experimental and Control groups Table 2 contains the data that was used to test the hypothesis. That data was generated from the posttest administered on the experimental and control groups.

Table 2

t-test of Post-test Mean Score of the Experimental and Control Group

\begin{tabular}{|l|r|r|l|l|l|}
\hline Groups & Mean & t-cal & t-tab & Df & Decision \\
\cline { 1 - 3 } Experimental (14) & 3584.00 & 0.08 & 1.71 & 26 & Significant \\
\cline { 1 - 2 } Control (14) & 3550.43 & & & & \\
\hline
\end{tabular}

$\mathrm{N}=28$

The data presented in table 2 reveals a higher mean for the Experimental group, and the t-test shows a significant difference between the Experimental and Control groups with a t- cal of 0.08 . The $t$-cal is less than the t-tab (table t') of 1.70. Therefore, the null hypothesis of 'no difference' is rejected - the two groups performed differently. The Experimental and the Control groups showed a significant difference. The Experimental group performed better than the Control group, which implies that the treatment (enhanced ergonomics) is effective.

3. There is no significant difference in the posttest mean score of the Male and Female in the Experimental

Table 3 Group

t-test of Posttest Mean Score of the Male and Female Experimental Groups

\begin{tabular}{|l|l|l|l|l|l|}
\hline Groups & Mean & t-cal & t-tab & df & Decision \\
\cline { 1 - 6 } $\begin{array}{l}\text { Male (8) } \\
\text { Female (6) }\end{array}$ & 4084.50 & 2.86 & 1.78 & 12 & Not Significant \\
\cline { 2 - 3 } & 2916.66 & & & & \\
\hline
\end{tabular}

The data presented in table 3 show that there is no statistically significant difference between the posttest performance of the male and female participants in the Experimental group. The $\mathrm{t}$ - cal ( $\mathrm{t}$ ' calculated) is 2.86 and is greater than the critical ' $\mathrm{t}$ ' (table ' $\mathrm{t}$ ') of 1.78 at $\mathrm{df}$ of 12 with 0.05 two-tailed significance level. The null hypothesis of 'no difference' is not rejected - the two groups performed equally.

\section{Discussion of Findings}

The results of this research reveal the important role of ergonomics in the productivity of office workers with reference to data entry works that rely heavily on the use of the computer. Although there is paucity of earlier research findings in Nigeria regarding this area, elsewhere in Ghana, Asante (2012) found out that poor office ergonomics has adverse effect on workers productivity just as in India (Vimalanathan and Ramesh Babu, 2017) identified environmental and physical ergonomics factors as playing very important role in officer workers' effectiveness. The findings of the present study that shows a better performance of participants with better furniture and equipment is in keeping with the cross-cultural studies reviewed. In addition, Idowu et al (2005) stressed that features of an office such as people, space, equipment, furniture and the environment, must fit together well for workers to feel healthy and comfortable and to be able to work efficiently and productively.

It is important to note as well that gender is not a significant factor of discrimination when ergonomics is concerned for the office workers. Both male and female require ergonomically fitted office, furniture and equipment to perform creditably well. The finding relating to no statistically difference in performance among the male and female participants confirm that every human need comfort to be able to perform. 


\section{Conclusions}

The post-test performance for the Experimental group was better than the Control group, implying that office workers with ergonomically fitted furniture, equipment and environment are very likely to perform better in their duties. Both male and female are affected by ergonomics as given no gender is hardwired to be alienated from comfortable work environment. Office workers would in the tertiary education would perform better with enhanced work environment irrespective of the gender. Tertiary educational institution would achieve high productivity from the officer workers if the work environment is fitted with ergonomically designed work environment, furniture and equipment

\section{Recommendations}

Based on the findings and conclusions of the study, the following recommendations were made:

1. Office workers in tertiary institutions in Nigeria should have a well-furnished office.

2. Officer workers in the tertiary institutions should be provided with appropriate ICT devices to work with and should be involved when procurement of such devices is due.

3. Office environment should allow for maximum comfort in terms of light, air and space.

4. No gender should be discriminated against in terms of the provision of ergonomically fitted offices and equipment.

\section{References}

Agomuo, E. E. (2005). Modern Office Technology, Issues, and Procedures and Practice. University of Nigeria Press Ltd. Bank/Bookshop Building Complex UNN.

Agboola, A. A. (2011). Towards Reducing Common Ergonomic Hazardsand Alleviating techno-stress Associated with the Adoption of Information and Communication Technology. International journal of innovation in the digital economy, 2(2), $56-65$.

Ahmad, U. N. U., Amin, S. M., \& Ismail W. K. W. (2009). The Impact of Tehnostress on Organizational Commitment among Malaysian Academic Librarians. Singapore Journal of library \& Information Management. Vol. 38.

Ahmed-Refat, A. G. R., Abdullah, H. M., Sahar, A. E. A., \& Rehab, A.E. H. (2008). Ergonomic aspect and Health hazards on computer workstations operators at Zagazig University: an occupational Risk Management Approach. Zagazig Journal of Occupational Health, 1 (1), 15 - 31.

Asante, K. (2012). The impact of office ergonomics on employee performance: A case study of the Ghana National Petroleum Corporation (GNPC). Kumasi: Kwame Nkrumah University of Science and Technology Repository

Awodi, Y. W. (2019). Polytechnic education in Nigeria: Opportunities for wealth and job creation, the journey so far. $24^{\text {th }}$ Convocation Lecture, at the Federal Polytechnic, Idah, Kogi State, Nigeria, May 11, 2019.

Costa, A.P. and Villarouco, V. (2012). Ergonomic analysis of the use of open-plan offices in Brazilian public sector offices. Retrieved from https://pdfs.semanticscholar.org>, 23/10/2018.

Emmanuel, O. D., Jonathan, F. O. \& Ayodeji A. A. (2014). Assessment of Ergonomic Hazards and techno-Stress among the Workers of Obafemi Awolowo University, Ile-Ife. Australian journal of business and management research, 4(1),27-34.

Federal Republic of Nigeria (2009). National Policy on Education. Abuja: NERDC Press.

Gary, D. (2008). Human Resource management. Canada: Pearson, Prentice Hall.

Gold, J., Driban, J., Yingling, V. and Komaroff, E. (2012). Characterization of Posture and Comfort in Laptop Users in Non-Desk Settings, in Applied Ergonomics, 43.

Idowu, B. O., Adedoyin R. A. \& Adagunodo R. E. (2005). Computer Related Repetitive Strain Injuries. Journal of the Nigerian Society of Physiotherapy. 15(1).

Kalu, O. (2009). Office Administration and Management. Lagos: Adecrown printers Ltd.

Laurig, W and Vedder, J. (2020). Ergonomics. https://iloencyclopaedia.org/contents/part-iv-66769/ergonomics52353

Lennart, D., Jasminka G., L., Sandra R. and Ida D. (2015). The Changing Face of Office Ergonomics. The Ergonomics open journal, 8, 38-56.

Mercado, S.M. (2015). Ergonomic design measures on work process and workplace layout in the selected structural and fabrication shops. Asia pacific journal of multidisciplinary research, 3(4), 86-97. Retrieved from www.apjmr.com, 6/5/2018.

Oborah, J. O. (2011). Basic ICT Skills and Keyboarding for Office Technology and Management. Lagos Adura Publishers.

Ogungbe, V (2020). The importance of polytechnic education in Nigeria. https://infoguidenigeria.com/importance-polytechnic-education-nigeria/

O'Neill (2013). New work place ergonomic research. Emerging risks and solutions. Retrieved from 
www.knoll.com/research/index.jsp on 12/5/2018.

Saniyer, J. and Penman, J. (2014): Ergonomics and Computer Use: Increasing the awareness of rural secondary school students. $47^{\text {th }}$ Annual Conference of Human factor and Ergonomics Society of Australia. Retrieved on 22/3/17 from www.Ergonomics.org.au

Sauter and Swanson (1996). S.L. Sauter, N.G. Swanson An ecological model of musculoskeletal disorders in office work S.L. Sauter, S.D. Moon (Eds.), Beyond Biomechanics: Psychosocial Aspects of Musculoskeletal Disorders in Office Work, Bristol (1996), pp. 3-20

Segun, O. O., Atinuke, R. A. and Akeem A. B. (2017). Ergonomics awareness and employee performance: an exploratory study. Retrievedfromhttps://www.researchgate.net/publication/322693455ergonomicsawareness-and-employee-performance on 14/7/2018.

Shin, G. and Hegde, S. (2010). User-Preferred Position of Computer Displays of Different Sizes and Configurations, in Proceedings of the Human Factors and Ergonomics Society, 54th Annual Meeting.

Sohbat, M, Oly, I. K., Haider, F. B., Mohiuddin, M and Probha, R. F. (2015). Facility layout of an Electronic/LED manufacturing Industry - A case Study. BSc Thesis of the Department of Mechanical and Production Engineering, Ahsanullah University, Dhakka, Banglandesh.

Vimalanathan, K. and Ramesh, B. T. (2017). A study on the effect of ergonomics on computer operating office workers in India. $J$ ergonomics, an open access journal 7(5). Retrieved from https://www.omicsonline.org>open-access

First A. Author (M'76-SM'81-F'87) and the other authors may include biographies at the end of regular papers. Biographies are often not included in conference-related papers. This author became a Member (M) of Association XXXX in 1976, a Senior Member (SM) in 1981, and a Fellow (F) in 1987. The first paragraph may contain a place and/or date of birth (list place, then date). Next, the author's educational background is listed. The degrees should be listed with type of degree in what field, which institution, city, state, and country, and year degree was earned. The author's major field of study should be lower-cased.

Second A. Author (M'76-SM'81-F'87) and the other authors may include biographies at the end of regular papers. Biographies are often not included in conference-related papers. This author became a Member (M) of Association XXXX in 1976, a Senior Member (SM) in 1981, and a Fellow (F) in 1987. The first paragraph may contain a place and/or date of birth (list place, then date). Next, the author's educational background is listed. The degrees should be listed with type of degree in what field, which institution, city, state, and country, and year degree was earned. The author's major field of study should be lower-cased. 